\title{
ResearchOnline@JCU
}

This is the author-created version of the following work:

Thorley, Craig, Beaton, Lara, Deguara, Phillip, Jerome, Britanny, Khan, Dua, and Schopp, Kaela (2020) Misinformation encountered during a simulated jury deliberation can distort jurors' memory of a trial and bias their verdicts. Legal and Criminological Psychology, 25 (2) pp. 150-164.

Access to this file is available from:

https://researchonline.jcu.edu.au/62865/

(C) 2020 The British Psychological Society

Please refer to the original source for the final version of this work: 
Misinformation encountered during a simulated jury deliberation can distort jurors' memory of a trial and bias their verdicts

Craig Thorley*, Lara Beaton, Phillip Deguara, Britanny Jerome, Dua Khan, Kaela Schopp Department of Psychology, James Cook University, Townsville, Australia University, Townsville, Australia, 4810. e-mail: craig.thorley@jcu.edu.au 


\begin{abstract}
Purpose. Jurors swear to base their verdicts solely on the evidence presented at trial. Their recall of a trial during deliberation can, however, be inaccurate, exposing other jurors to misinformation about the trial. This study examined whether jurors who are exposed to misinformation during a simulated deliberation, where the misinformation supports the prosecution's case, will misremember the misinformation as appearing during a trial and be more likely to reach a guilty verdict. It also examined whether allowing jurors to take notes during a trial, and refer to those notes throughout, stops these potentially harmful effects. Methods. One hundred and twenty-four participant jurors watched a murder trial. Half were allowed to take notes. They then read a transcript of a deliberation that either contained or did not contain six pieces of pro-prosecution misinformation. Afterwards they reached a verdict. Finally, they completed a source monitoring test that required indicating whether the misinformation, and actual trial information, appeared during the trial.
\end{abstract}

Results. Jurors exposed to misinformation misremembered it as appearing during the trial. Those who misattributed the most misinformation to the trial were most likely to reach a guilty verdict. Note taking, and note access, did not prevent these effects.

Conclusions. Jurors can make mistakes when recalling a trial during deliberation but the consequences of this were largely unknown. This study provides initial evidence that their mistakes may distort other jurors' recollection of the trial and bias their verdicts. Attempts to replicate these findings using live deliberations are encouraged to determine their generalisability.

Keywords: juror, memory conformity, verdict, misinformation, note taking Acknowledgement: Thanks to Christine Ruva for supplying the trial video used in this study 


\section{Misinformation encountered during a simulated jury deliberation can distort jurors' memory of a trial and bias their verdicts}

In the United States, people accused of a crime punishable by incarceration for more than six months have a right to a trial by jury (Baldwin v. New York, 399 U.S. 66 (1970)). Other countries have similar legislation (e.g., England and Wales). In some countries, civil law disputes can also be tried by juries. Juries therefore play an important role in many legal systems. During criminal trials, jurors listen to evidence from the prosecution that the accused committed a crime and, often, counter-evidence from the defence that the accused did not. After listening to the evidence, the jurors must recollect it, deliberate it, and reach a verdict. Jurors often take an oath swearing to base their verdict solely on the evidence presented during the trial. It is therefore important their recollection of the trial is accurate or unjust verdicts could be reached. As discussed shortly, a juror's recall of a trial during deliberation can be inaccurate, exposing fellow jurors to misinformation about the trial. The primary aim of the present study was to examine whether jurors who are exposed to misinformation during a simulated deliberation, where the misinformation supports the prosecution's case, will misremember that misinformation as appearing during the trial and be more likely to reach a guilty verdict as a result of this. A secondary aim of the study was to examine whether permitting jurors to take notes during the trial, and refer to these notes during the simulated deliberation, protects against these potentially harmful effects.

\section{Jurors' Recollection of Evidence and Verdicts}

Our understanding of how well jurors recall trials comes from mock-juror research. That research shows an individual juror's recall of trial evidence can be incomplete and inaccurate (e.g., Costabile \& Klein, 2005; Fitzgerald, 2000; Lorek, Centifanti, Lyons, \& Thorley; 2019; Pritchard \& Keenan, 2002). To contextualise this, two examples are offered. Focussing on incompleteness, Lorek et al. (2019) found jurors in a murder trial could only 
recall, on average, six of the 16 most important pieces of evidence. Focussing on inaccuracy, Fitzgerald (2000) found jurors misremembered critical evidence from a civil trial where four plaintiffs sued a chemical company which allegedly polluted their drinking water and made them ill. Specifically, some jurors recalled all plaintiffs developing cancer but only one did.

Importantly, several studies also show the type of evidence jurors recollect and forget, in terms of whether it is pro- or anti-prosecution, predicts their verdicts. For example, Lorek et al. (2019) found that jurors who remembered more pro-prosecution evidence from a murder trial were more likely to reach guilty verdicts, whilst jurors who remembered more anti-prosecution evidence were more likely to reach not guilty verdicts. Similarly, Costabile and Klein (2005) found jurors who forgot about a critical piece of pro-prosecution evidence from a murder trial were less likely to reach a guilty verdict than jurors who remembered it.

Studies also show that exposure to pro-prosecution misinformation, via pre-trial publicity (PTP) surrounding a trial, can distort jurors' recollection of a trial and bias their verdicts (see Ruva, 2018, for a review) ${ }^{1}$. More specifically, jurors exposed to pro-prosecution PTP can commit source monitoring errors whereby they incorrectly remember the PTP as appearing during the trial and, importantly, those who misattribute the most PTP to the trial are most likely to believe the accused is guilty (e.g., Ruva \& Guenther, 2015, 2017; Ruva \& McEvoy, 2008; Ruva, McEvoy, \& Bryant, 2007; see Johnson, Hashtroudi, \& Lindsay, 1993, for more on source monitoring errors generally).

\section{Misinformation During Deliberations}

Misinformation can be imparted during jury deliberations. Research shows that jurors exposed to pro-prosecution PTP will discuss it during deliberation, even if instructed not to (e.g., Ruva \& Guenther, 2015; Ruva \& LeVasseur, 2012). More generally, jurors also make mistakes when recalling trial evidence during deliberation, exposing other jurors to

\footnotetext{
${ }^{1}$ PTP is classed as misinformation as it is information that does not appear during a trial.
} 
misinformation (e.g., Pritchard \& Keenan, 2002). Worryingly, jurors rarely correct misinformation that is introduced during deliberation (e.g., Pritchard \& Keenan, 2002; Ruva \& Guenther, 2015; Ruva \& LeVasseur, 2012)². Currently, it is unknown whether jurors who are exposed to pro-prosecution misinformation during deliberation will later misremember that misinformation as appearing during the trial and, if so, whether this increases the likelihood of those jurors reaching a guilty verdict.

Recollection of an event can change after exposure to another person's alternative account of the event. This effect is known as memory conformity (Wright, Self, \& Justice, 2000) or the social contagion of memory (Roediger, Meade, \& Bergman, 2001). Memory conformity has been observed in legal cases where co-witnesses to a crime have discussed it, one has imparted misinformation, and the other witnesses have incorporated the misinformation into their subsequent witness statements (see Wright, Memon, Skagerberg, \& Gabbert, 2009). Memory conformity can be induced in the laboratory using a variety of methods and it can occur regardless of whether participants encounter new, often erroneous, information about an experienced event from another person in a face-to-face interaction or if the participants simply read another person's conflicting account of the event (Gabbert, Memon, Allan, \& Wright, 2004; Meade \& Roediger, 2002; Paterson \& Kemp, 2006). Memory conformity occurs for several reasons, including conformity, but source monitoring errors can occur whereby participants misremember the new information as part of the event (Wright et al., 2009). Memory conformity effects are robust, so it is possible that jurors who are exposed to pro-prosecution misinformation during deliberation will commit source monitoring errors and misremember the misinformation as appearing during the trial.

\footnotetext{
${ }^{2}$ Misinformation that is corrected during deliberation could still potentially influence jurors' recollection of the trial and their verdicts. Research on the Continued Influence Effect shows misinformation can continue influencing beliefs even after being corrected (see Lewandowsky, Ecker, Seifert, Schwarz, \& Cook, 2012, for a review).
} 
Moreover, given that a juror's recollection of a trial can influence that juror's verdict, it is possible that jurors who commit the most source monitoring errors would be most likely to reach a guilty verdict.

\section{Note Taking and Memory of Evidence}

Encouraging jurors to take notes during a trial, and giving them access to those notes during deliberation, could potentially stop any misinformation they encounter during deliberation from distorting their recollection of the trial. Research shows that permitting note taking during a trial improves jurors' recollection of the trial (e.g., ForsterLee, Horowitz, \& Bourgeois, 1994; Hope, Eales, \& Mirashi, 2014; Rosenhan, Eisner, \& Robinson, 1994; Thorley, Baxter, \& Lorek, 2016). This primarily occurs as note taking deepens jurors' encoding of trials, making trials more memorable (ForsterLee et al., 1994; Thorley et al., 2016). If note taking jurors have an improved recollection of a trial and can consult their notes to refresh their memory of it, they may dismiss any misinformation encountered during deliberation. This possibility has not previously been investigated.

\section{Aims and Hypotheses}

The primary aim of the present study was to examine whether jurors who are exposed to pro-prosecution misinformation during a simulated deliberation will incorporate that misinformation into their recollection of the trial and, if so, whether this increases the likelihood of those jurors reaching a guilty verdict. To examine this, participant jurors (henceforth, jurors) watched a murder trial and then read a transcript of a deliberation that included either six pieces of pro-prosecution misinformation or none. Whilst reading the transcript they were asked to pretend they were part of the deliberation. The jurors then reached a verdict and completed a source monitoring test which asked them to identify the source of the misinformation. Past PTP and memory conformity research suggests jurors exposed to pro-prosecution misinformation during our simulated deliberation will commit 
source monitoring errors and misremember the misinformation as appearing during the trial. Past PTP research also suggests that the more misinformation the jurors misattribute to the trial, the more likely they will be to reach a guilty verdict. A secondary aim of the study was to examine whether permitting jurors to take notes during the trial, and then refer to these notes throughout, reduces source monitoring errors. The present study is the first to examine the impact of note taking on susceptibility to memory conformity/source monitoring errors, so this issue is exploratory.

\section{Method}

\section{Participants}

There were 124 jurors, aged $18-59(M=25.36$ years, $M d n=21.00 ; S D=9.83)$. Eighty-two identified as female, 41 as male, and one did not specify. All were students enrolled in undergraduate psychology classes. They were recruited via an online-sign up system and participated for course credit. The study received institutional ethical approval.

Focussing on statistical power, large memory conformity effects are often observed in studies using source monitoring tests (e.g., Meade, McNabb, Lindeman, \& Smith, 2017, obtained a $\eta^{2}$ of .20; Thorley \& Christiansen, 2018, a $\eta_{p}^{2}$ of .42). G*Power 3 (Faul, Erdfelder, Lang, \& Buchner, 2007) indicated a sample size of 52 participants would be required to achieve power $>.80$ in our main 2 x 2 ANOVA source monitoring analyses if large effects were expected (Cohen's $\mathrm{f}=.40)$ and alpha was .05. Similarly, PTP studies show exposure to pro-prosecution misinformation can have a large effect upon jurors' verdicts (e.g., Ruva \& Guenther, 2017, obtained a Cramer's V's of .35 and .31; Ruva, 2016, a Cramer's V of .31). G*Power 3 indicated a sample size of 25 participants would be required to achieve power $>.80$ in our main one-tailed logistic regression verdict analysis if a large odds-ratio were expected (OR = 4.00; see Ferguson, 2009), alpha was .05, and $\operatorname{Prob}(\mathrm{Y}=1 \mid \mathrm{X}=1)$ Ho $=.50$. 


\section{Design}

The study had a 2 x 2 between-subjects design. The first independent variable was Transcript Type, with jurors exposed to a deliberation transcript that either did or did not contain pro-prosecution misinformation. The second independent variable was Note Taking, with jurors either eligible or not eligible to take notes during the trial. There were two primary dependent variables. The first was the proportion of misinformation jurors misremembered as appearing during the trial. The second was their verdict (guilty or not guilty). Secondary dependent variables are discussed in the Stimuli section.

\section{Stimuli}

The Trial. Jurors watched 30 min of footage from a real murder re-trial where a man, Dan Bias, was accused of shooting and killing his wife, Lise Bias (New Jersey vs. Bias, 1991). The defence argued Lise had a history of suicidal thoughts and shot herself. The footage contained the prosecution and defence's opening arguments, the cross-examination of seven witnesses, and both attorneys' closing arguments. The verdict was not shown. Results from previous research suggest this trial is ambiguous regarding the defendant's guilt (e.g., Hope, Memon, \& McGeorge, 2004; Pritchard \& Keenan, 1999; Ruva \& McEvoy, 2008; Thorley, 2016). Our jurors were unfamiliar with the trial.

The Deliberation Transcripts. Jurors read one of two transcripts. One transcript had 24 statements about the evidence and legal arguments in the trial. The other transcript had the same 24 statements and six additional statements conveying pro-prosecution misinformation that did not appear in the trial. The 24-statement transcript was created first by having six people, who did not participate in the current study, watch the trial video and deliberate the evidence afterwards as though they were real jurors. That deliberation was recorded, transcribed, and condensed to a 24 statement/1033-word discussion about the strengths and weaknesses of a range of trial evidence and legal arguments. Each juror was assigned a 
number in the transcript (e.g., Juror 1) and each contributed four statements. Statements were selected for the transcript that provided a balanced view of the evidence and legal arguments, meaning the transcript did not intentionally favour the prosecution or defence's case. Table 1 has an example of three consecutive statements by three jurors who are debating the merits of some forensic evidence.

Table 1

Three consecutive statements from the juror deliberation transcript discussing trial evidence

Juror Statement

Juror 2 The police also admitted they did not test Dan for gunshot residue to see if he had recently fired a gun. We therefore can't really know what happened.

Juror 3 There was, however, no gunshot residue in Lise's hair. If you remember, the coroner said there would be residue if Lise had shot herself.

Juror 6 That is true but the coroner also admitted to rinsing the hair before testing it. As the Chief Medical Examiner later explained, the rinsing may have removed any gunshot residue that was there. We therefore can't know whether Lise killed herself or not.

The 30-statement transcript was created by adding in six pieces of pro-prosecution misinformation at junctures where related information was discussed. The six pieces of misinformation were modelled on six pieces of PTP used by Ruva et al. (2007) in a study featuring this same trial. Each juror contributed one piece of misinformation. An example is Juror 3 incorrectly stating "One of the witnesses did say Dan had a bad temper. Maybe he did lose his temper with Lise that night and killed her. It sounds like he could 'lose it' sometimes". No other jurors confirmed or challenged the accuracy of the misinformation. The 30-statement transcript, with the misinformation italicised, is in the Supporting Information. 
The Source Monitoring Test. The source monitoring test contained 24 items. Six items restated the misinformation described above, 12 correctly restated information from the trial, and six stated new information that did not appear in the trial or transcripts. This new information was chosen from a selection of errors made by mock jurors when recalling this same trial in an unpublished study. The correct and new information provide a measure of whether the jurors across the four conditions remembered the trial equally as well. The response options asked jurors to indicate whether (and if so, where) they had previously encountered each piece of information. The options were Trial Only, Trial and Deliberation, Deliberation Only, Neither Trial nor Deliberation, and Don't Know. The source monitoring test items appear in the Supporting Information. For interested readers, a breakdown of how often jurors remembered each piece of information as appearing during the trial also appears.

\section{Procedure}

Up to four jurors at a time completed the study in a quiet laboratory at individual partitioned PC terminals. The study was hosted online. The jurors first read an information sheet telling them they would act as jurors whilst watching footage from a murder trial. After providing informed consent, the jurors read instructions modelled on those a real juror receives at the start of a trial. The instructions explained their role during a trial, the structure of a trial, and the definition of reasonable doubt they must consider when reaching their verdict. The jurors were then randomly allocated to either the note taking or non-note taking conditions. Jurors in the former were told they could take notes when watching the trial and refer to those notes throughout the study. They were not permitted to take notes at any other time. Modelling the experience of real jurors, no information was given about what to write down. The note takers were then given a blank notepad and pen for note taking. All jurors then donned headphones and watched the trial. 
After watching the trial, the jurors were randomly assigned to read one of the two deliberation transcripts. Before reading the transcript, they were told it was a partial transcript of a real jury deliberation by six former jurors. They were also asked to pretend they were part of that deliberation and told they may privately agree or disagree with the statements made. The jurors were then asked to read the transcript once from start to finish. This task was self-paced to ensure they had enough time to read the entire transcript. Afterwards, the jurors completed a demographic questionnaire, reached a verdict, and expressed their confidence in their verdict on a scale of $1-7(1=\mathrm{I}$ am certain he is not guilty; $4=\mathrm{I}$ am unsure whether he is guilty or not guilty; 7 = I am certain he is guilty). The jurors then completed the source monitoring test, with that test being self-paced and the item order randomised. Debriefing then occurred and the study ended. The study lasted approximately $1 \mathrm{hr}$.

\section{Results}

The untransformed data used in all analyses can be accessed from the Open Science Framework via the following link: https://osf.io/yaqcb/

\section{Trial Evidence Recollection}

Analyses in this section focussed on the proportion of pro-prosecution misinformation, new information, and correct information from the source monitoring test that jurors remembered as appearing during the trial. For example, if a juror incorrectly remembered that three of the six pieces of misinformation appeared during the trial, the proportion would be .50 . Table 2 shows the proportion of each type of information that was remembered as appearing during the trial. When calculating these proportions, 'Trial Only' and 'Trial and Deliberation' source monitoring test responses were summed as both indicate a belief that the information appeared during the trial.

The proportions for each type of information were non-normally distributed. For the misinformation and new information, the data was positively skewed across most conditions 
and failed to pass the Shapiro-Wilk tests of normality (all $p^{\prime} s^{<.011) . ~ F o r ~ t h e ~ c o r r e c t ~}$ information, the data was negatively skewed and failed to pass the Shapiro-Wilk tests of normality (all $p^{\prime} s^{<.006)}$. The data was not, therefore, suitable for parametric tests. Consequently, the data was transformed using an Aligned Rank Transformation (Higgins \& Tashtoush, 1994; Wobbrock, Findlater, Gergle, \& Higgins, 2011) via the latter's ARTool (see Kay \& Wobbrock, 2019, for an R Package version). This tool aligns data (see Hodges \& Lehmann, 1962) and applies averaged ranks to it. Standard factorial ANOVA's can then be used to analyse the data but those tests are non-parametric (see Wobbrock et al., 2011, or Mansouri, Paige \& Surles, 2004, for overviews). Here, 2 x 2 non-parametric betweensubjects ANOVA's were used to compare the proportion of each information type that was remembered as appearing during the trial across the four conditions.

The proportion of pro-prosecution misinformation misremembered as appearing during the trial was examined first. Overall, $22 \%(M=.22, M d=.17, S D=.23)$ of the misinformation was misattributed to the trial. There was a significant main effect of Transcript Type, with jurors who read a transcript containing misinformation being more likely to misremember that misinformation as appearing during the trial $(M=.31, M d=.33$, $S D=.26)$ than those who read a transcript with no misinformation $(M=.13, M d=.17, S D=$ $.15), F(1,120)=21.62, p<.001, \omega^{2}=.14$. There was no significant main effect of Note Taking, with similar amounts of misinformation misattributed to the trial by note takers $(M=$ $.23, M d=.17, S D=.24)$ and non-note takers $(M=.20, M d=.17, S D=.22), F(1,120)=0.40$, $p=.85, \omega^{2}=<.001$. There was also no significant Transcript Type $\mathrm{x}$ Note Taking interaction, $F(1,120)=0.31, p=.58, \omega^{2}=<.001$. 
Table 2

The proportion of pro-prosecution misinformation, new information, and correct information that jurors believed appeared during a trial after reading a deliberation transcript containing the misinformation or a transcript without any misinformation. Standard Deviations are shown in parentheses

\begin{tabular}{lcccc}
\hline Information Type & \multicolumn{2}{l}{ Misinformation Transcript } & \multicolumn{2}{l}{ No Misinformation Transcript } \\
\hline & $\underline{\text { Note Takers }}$ & $\underline{\text { No Notes }}$ & $\underline{\text { Note Takers }}$ & $\underline{\text { No Notes }}$ \\
Misinformation & $.31(.28)$ & $.31(.24)$ & $.16(.17)$ & $.10(.13)$ \\
New & $.29(.19)$ & $.26(.19)$ & $.28(.20)$ & $.30(.27)$ \\
Correct & $.86(.10)$ & $.85(.11)$ & $.84(.11)$ & $.87(.10)$ \\
\hline
\end{tabular}

Note. Each value was calculated by summing the proportion of 'Trial Only' and 'Trial and Deliberation' source monitoring test responses as both responses indicate that participant jurors believed the information appeared during the trial

Overall, $28 \%(M=.28, M d=.33, S D=.21)$ of the new information was misremembered as appearing during the trial. The ANOVA analysing this information revealed no significant main effects of Transcript Type, $F(1,120)=0.02, p=.90, \omega^{2}=<.001$, or Note Taking, $F(1,120)=0.52, p=.47, \omega^{2}=<.001$, and no significant interaction between the two, $F(1,120)=0.62, p=.43, \omega^{2}=<.001$.

Overall, $85 \%(M=.85, M d=.83, S D=.10)$ of the correct information was remembered as appearing during the trial. The ANOVA analysing this information revealed no significant main effects of Transcript Type, $F(1,120)=<0.01, p=.99, \omega^{2}=<.001$, or Note Taking, $F(1,120)=0.60, p=.44, \omega^{2}=<.001$, and no significant interaction between the two, $F(1,120)=0.31, p=.58, \omega^{2}=<.001$. 
To summarise, memory conformity occurred as jurors who were exposed to proprosecution misinformation when reading a deliberation transcript, relative to those who were not, were more likely to believe the misinformation appeared during the trial. Note taking, and later note access, had no impact upon this. Importantly, jurors exposed to misinformation were no worse at remembering the trial generally as they performed as well as those not exposed to it when deciding whether new information and correct information appeared during the trial.

\section{Verdict Related Analyses}

Fifty-two of the 124 jurors (41.93\%) reached a guilty verdict and this value is representative of what occurred within each condition. A 2 × 2 Chi-Squared analysis confirmed there was no significant association between Transcript Type and Note Taking when the number of guilty verdicts reached are considered, $\chi^{2}(1, n=52)=0.01, p=.99$, Cramer's $V=.001$. Additionally, a Mann-Whitney U test revealed that those who reached a guilty verdict were more confident in their verdicts $(M=5.96, M d=6.00 ; S D=0.84)$ than those who reached a not guilty verdict $(M=3.10, M d=3.00 ; S D=1.15), W=141.50$, $p<.001, r=.92$.

Jurors exposed to pro-prosecution misinformation varied in how much of it they believed appeared during the trial. Importantly, a logistic regression showed that the more misinformation those jurors misremembered as appearing during the trial, the more likely they were to reach a guilty verdict, $\chi^{2}(58)=5.41, p=.02$, Cox and Snell $R^{2}=0.09$, Nagelkerke $R^{2}=.12, \mathrm{OR}=12.38($ see Figure 1$)$ 


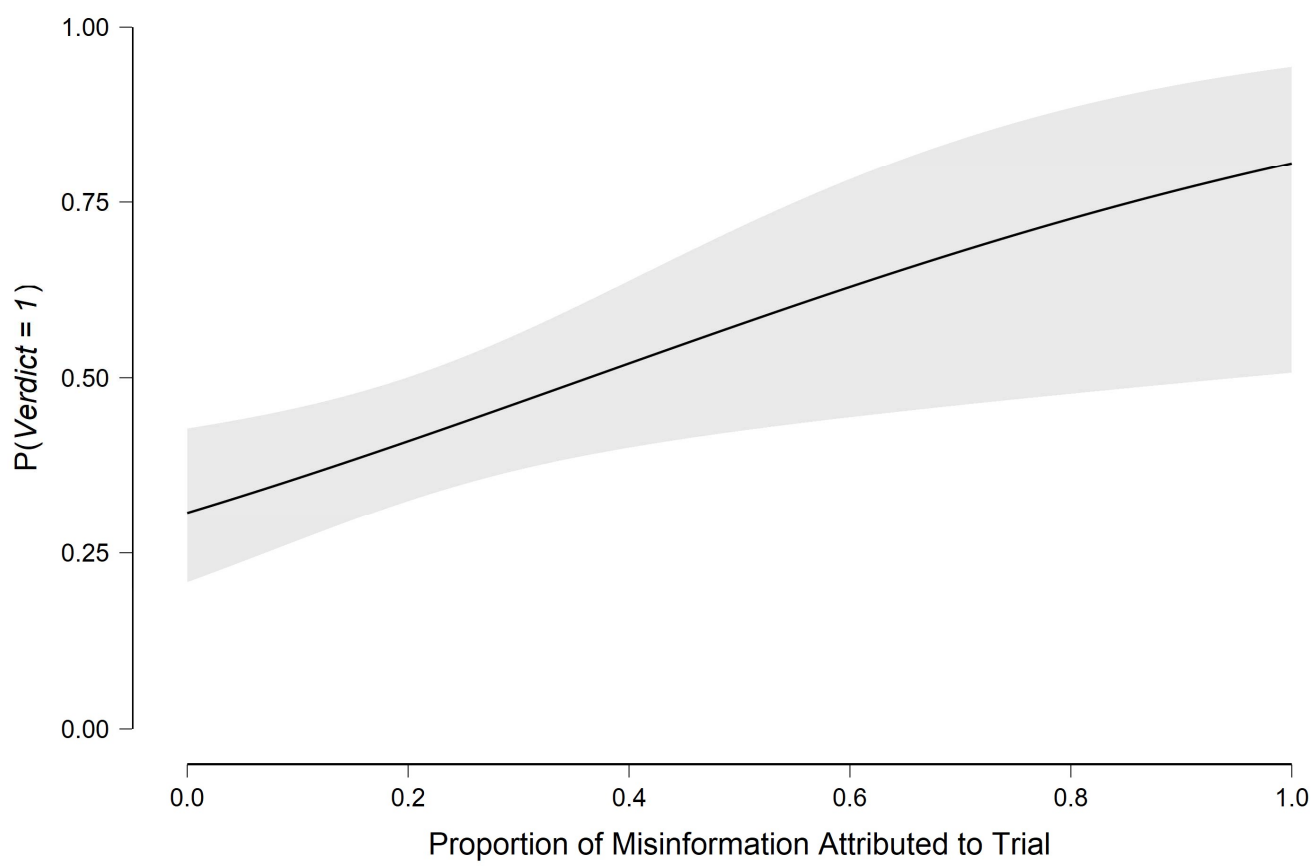

Figure 1. A conditional estimate plot showing the probability of jurors reaching a guilty verdict increases as the proportion of pro-prosecution misinformation they misremember as appearing during a trial increases

A limitation of our study design is that it does not allow us to determine whether simply reading a deliberation transcript (irrespective of its content) influenced our jurors' verdicts. To try and shed light on this, we ran a separate pilot study where jurors who did not read any transcript/did not take any notes also watched the trial video and reached a verdict. There were 33 jurors in this pilot study $(M$ Age $=21.76$ years, $M d n=19.00 ; S D=6.71$, Age range $=18-41 ;$ Female $=26$, Male $=7)$ and they were recruited using the same method as all other jurors. Overall, $54.54 \%$ of the jurors reached a guilty verdict, which is slightly higher than the percentage across the four main conditions in our study $(41.93 \%)$. This is considered further in the General Discussion. 


\section{Note Taking Equivalency and Accuracy}

This final section considers whether the jurors' notes differed across the two note taking conditions in terms of the number of words noted down and their content ${ }^{3}$. Two of the authors independently scored these measures and no disagreements occurred. Those exposed to misinformation noted down, on average, 118.75 words $(S D=74.12)$ whereas those not exposed to any misinformation noted down, on average, $99.62(S D=62.59)$. Both distributions passed the Shapiro-Wilk test of normality (both $p$ 's $>.13$ ) and a between-subjects t-test showed their Means did not significantly differ, $t(55)=1.05, p=.30, d=0.28$. Those exposed to misinformation also noted down, on average, $5.36(S D=2.20)$ pieces of trial information that later appeared as correct information on the source monitoring test whereas those not exposed to any misinformation noted down, on average, $4.86(S D=2.46)$. Again, both distributions passed the Shapiro-Wilk test of normality (both $p$ 's $>.33$ ) and a betweensubjects t-test showed their Means did not significantly differ, $t(55)=0.80, p=.43, d=0.21$. Importantly, no jurors noted down any information that later appeared as new information on the source monitoring test, but two did independently note down one piece of misinformation that later appeared on this test. Note taking was therefore equivalent, and highly accurate, across conditions.

\section{General Discussion}

This study has three main findings. First, jurors who watched a murder trial, and then read a jury deliberation transcript containing pro-prosecution misinformation, later believed $31 \%$ of that misinformation appeared during the trial. Second, and most importantly, jurors who misremembered the most misinformation as appearing during the trial were also most

\footnotetext{
${ }^{3}$ One juror from each note taking condition did not appear in these analyses. Their notes did not have their participant ID's written on them, making it impossible to know who the notes belonged to.
} 
likely to reach a guilty verdict. Third, allowing jurors to take notes during the trial, and then refer to those notes throughout the study, did not reduce these effects.

\section{Jurors' Recollection of the Trial and Verdicts}

Our first main finding was predicted. Past research had shown that if mock jurors are exposed to pro-prosecution misinformation via PTP then they can commit source monitoring errors and misattribute that misinformation to the trial (e.g., Ruva \& Guenther, 2015, 2017; Ruva \& McEvoy, 2008; Ruva et al., 2007). Moreover, memory conformity research had shown that if one person encounters erroneous information about an experienced event from another, the former can incorporate that misinformation into their recollection of the event (e.g., Gabbert et al., 2004). The current study, however, provides the first demonstration that memory conformity effects can occur in the context of a trial whereby jurors who are exposed to pro-prosecution misinformation, purportedly from a fellow juror, will incorporate that misinformation into their recollection of the trial. Importantly, when the jurors' memory of the trial was assessed in other ways, such as asking them to correctly identify actual trial information, those exposed to the misinformation and those not exposed to it performed equally well. Thus, our memory conformity effects did not occur as those jurors who were exposed to the misinformation had a worse memory of the trial or were more error prone.

As an aside, readers will have noticed $28 \%$ of the new items on the source monitoring test were misremembered as appearing during the trial. That number is quite high and could reflect the fact that these items, selected from errors made by jurors in an unpublished study, were semantic variants of trial facts (e.g., one stated the gun used in the shooting was a Colt but it was a Magnum). People are prone to confusing semantically related studied and nonstudied information (e.g., Roediger \& McDermott, 1995).

Our second main finding was also predicted. Previously, PTP research had shown that the more pro-prosecution misinformation jurors misattribute to a trial, the more likely they 
are to believe the accused is guilty (Ruva \& Guenther, 2015; Ruva \& McEvoy, 2008; Ruva et al., 2007). The current study, however, is the first to show a similar association when the misinformation derives from another juror during a simulated deliberation.

\section{Note Taking and Memory Accuracy}

Exploratory analysis was used to examine whether jurors who took notes during the trial, and who could later refer to those notes during the simulated deliberation, would be inoculated against memory conformity/source monitoring errors. As mentioned, they were not. Note taking has previously been found to improve jurors' recall of trial information (e.g., ForsterLee et al., 1994; Hope et al., 2014; Rosenhan et al., 1994; Thorley et al., 2016). It is unclear if a similar enhancement occurred here as we did not ask jurors to recall the trial. Even if note taking enhanced jurors' recall of the trial, it is perhaps unsurprising that it did not stop the spread of misinformation. In other domains, such as eyewitness memory, there is often no relationship between recall completeness and accuracy (e.g., Marquis, Marshall, \& Oskamp, 1972; Van Koppen \& Lochun, 1997; Wells, 1985). It is possible that note taking jurors assumed any misinformation they encountered during deliberation was something they neglected to note down during the trial/had since forgotten and therefore assumed it was part of the trial. Further research, however, would be needed to determine why note taking, and note access, did not stop memory conformity/source monitoring errors.

\section{Implications, Limitations, and Future Directions}

Our study tentatively suggests that if jurors erroneously recall pro-prosecution misinformation during deliberation, other jurors will incorporate that misinformation into their memory of the trial and be more likely to reach a guilty verdict as a result of this. Our study therefore identifies a previously unidentified factor that may influence jurors' verdicts. There are, however, important limitations to the current study that must be addressed before any claims can be made about the generalisability of its findings. 
Perhaps the biggest limitation is that jurors were exposed to pro-prosecution misinformation via a deliberation transcript and not during an actual deliberation. Thus, the means by which our jurors encountered misinformation was artificial. It remains to be determined whether the effects observed here would replicate if jurors were exposed to proprosecution misinformation during an actual deliberation where they could discuss any misinformation they were exposed to and debate its veracity. This could be examined in the laboratory by having a confederate juror introduce the misinformation during a live deliberation. In defence of our methodology, memory conformity effects do occur regardless of whether misinformation is encountered in a face-to-face interaction or written communication (e.g., Gabbert et al., 2004; Meade \& Roediger, 2002; Paterson \& Kemp, 2006), jurors rarely correct misinformation encountered during deliberations (e.g., Pritchard \& Keenan, 2002; Ruva \& Guenther, 2015; Ruva \& LeVasseur, 2012), and exposure to proprosecution misinformation can increase the likelihood of jurors reaching a guilty verdict (e.g., Ruva \& Guenther, 2015, 2017; Ruva \& McEvoy, 2008; Ruva et al., 2007). Given the above, we would hope our findings are not simply an artefact of our methodology.

Another limitation associated with our stimuli is that the study centred on one trial where the evidence is ambiguous regarding the defendant's guilt (e.g., Hope et al., 2004; Pritchard \& Keenan, 1999; Ruva \& McEvoy, 2008; Thorley, 2016). Every trial is unique (e.g., they differ in how strong the prosecution's case is). The misinformation used here was also specific to this trial and the type of misinformation jurors may encounter in other trials would differ. This latter point is important as the way misinformation is phrased influences both the likelihood of it distorting recollection of an event (e.g., Sharman \& Powell, 2012) and the likelihood of it continuing to influence recollection if refuted (Rich \& Zaragoza, 2016). It therefore remains to be determined whether any effects observed here would replicate if another trial or other misinformation was used. 
A further limitation of our study is that the population validity is reduced slightly due to a student sample being used. In defence of this, memory conformity effects do occur in non-student samples (e.g., Davis \& Meade, 2013; Gabbert, Memon, \& Allen, 2003) and a meta-analysis of 53 mock-juror studies has shown student and community samples reach similar verdicts (Bornstein et al., 2017). Source monitoring errors, however, do increase with age (e.g., Cohen \& Faulkner, 1989). Thus, it is possible the memory conformity effects observed here would be greater in older jurors.

The final limitation to be discussed is that the design of our study prevents us from knowing whether simply reading a deliberation transcript, irrespective of its content, influenced jurors' verdicts. We do, however, feel this is unlikely. Overall, our jurors were fairly evenly split in their verdicts. Comparable splits have been observed in past studies where jurors watched this same trial video but did not read a deliberation transcript afterwards (e.g., Hope et al., 2004; Pritchard \& Keenan, 1999; Ruva et al., 2007; Thorley, 2016). We also ran a separate pilot study where jurors watched the trial/did not read a deliberation transcript afterwards and found a fairly even split in their verdicts. When comparing the percentage of guilty verdicts in our actual study (41.93\%) and pilot study (54.54\%), readers may question whether reading a transcript made jurors less likely to reach a guilty verdict. Whilst we cannot rule this out, the aforementioned past studies have sometimes found that jurors (who have not read a transcript) reach fewer guilty verdicts than not guilty verdicts (e.g., Pritchard \& Keenan, 1999, found 46\% of jurors reached a guilty verdict). There is no obvious reason why jurors who watch this trial do not consistently favour one verdict and the differences across studies may reflect individual differences in the makeup of the samples. Given that the verdicts in our study are comparable to several past studies where jurors have watched this same trial video but not read a transcript afterwards, 
we feel it is unlikely that being exposed to a transcript in our study influenced our jurors' verdicts.

\section{Conclusions}

This study examined whether exposing jurors to pro-prosecution misinformation, by having them read a transcript of an erroneous jury deliberation, can distort their recollection of a trial and bias their verdicts. Unfortunately, from a legal perspective, the jurors incorporated the misinformation into their recollection of the trial and those who incorporated the most were also most likely to reach a guilty verdict. Permitting the jurors to take notes during the trial, and then later refer to those notes, did not stop these effects. This study makes legal professionals and other researchers aware of a previously unidentified, but important, factor that could potentially bias jurors' recollection of a trial and shape their verdicts. Future research using live deliberations is recommended to provide a more authentic investigation of these issues. 


\section{References}

Baldwin v. New York, 399 U.S. 66 (1970)

Bornstein, B. H., Golding, J. M., Neuschatz, J., Kimbrough, C., Reed, K., Magyaries, C., \& Luecht, K. (2017). Mock juror sampling issues in jury simulation research: A metaanalysis. Law and Human Behavior, 41, 13-28. doi:10.1037/lhb0000223

Cohen, G., \& Faulkner, D. (1989). Age Differences in Source Forgetting: Effects on Reality Monitoring and on Eyewitness Testimony. Psychology and Aging, 4(1), 10-17. doi: $10.1037 / / 0882-7974.4 .1 .10$

Costabile, K. A., \& Klein, S. B. (2005). Finishing strong: Recency effects in juror judgments. Basic and Applied Social Psychology, 27, 47-58. doi:10.1207/s15324834basp2701_5

Davis, S. D., \& Meade, M. L. (2013). Both young and older adults discount suggestions from older adults on a social memory test. Psychonomic Bulletin \& Review, 20, 760-765. doi:10.3758/s13423- 013-0392-5

Faul, F., Erdfelder, E., Lang, A.-G., \& Buchner, A. (2007). G*power 3: A flexible statistical power analysis program for the social, behavioural, and biomedical sciences. Behavior Research Methods, 39, 175-191. doi:10.3758/BF03193146

Ferguson, C. J. (2009). An effect size primer: a guide for clinicians and researchers. Professional Psychology: Research and Practice, 40, 532-538. doi:10.1037/a0015808

Fitzgerald, J. M. (2000). Younger and older jurors: The influence of environmental supports on memory performance and decision making in complex trials. The Journals of Gerontology Series B: Psychological Sciences and Social Sciences, 55, 323-331. doi:10.1093/geronb/55.6.P323

ForsterLee, L., Horowitz, I. A., \& Bourgeois, M. (1994). Effects of notetaking on verdicts and evidence processing in a civil trial. Law and Human Behavior, 18, 567-578. doi: 10.1007/BF01499175 
Gabbert, F., Memon, A., \& Allan, K. (2003). Memory conformity: Can eyewitnesses influence each other's memories for an event? Applied Cognitive Psychology, 17, 533-543. doi:10.1002/acp.885

Gabbert, F., Memon, A., Allan, K., \& Wright, D. B. (2004). Say it to my face: Examining the effects of social encountered misinformation. Legal and Criminological Psychology, 9, 215-227. doi:10.1348/1355325041719428

Higgins, J. J., \& Tashtoush, S. (1994). An aligned rank transform test for interaction. Nonlinear World, 1, 201-211

Hodges, J. L., \& Lehmann, E. L. (1962). Rank methods for combination of independent experiments in analysis of variance. The Annals of Mathematical Statistics, 33, 482497. doi:10.1214/aoms/1177704575

Hope, L., Eales, N., \& Mirashi, A. (2014). Assisting jurors: Promoting recall of trial information through the use of a trial-ordered notebook. Legal and Criminological Psychology, 9, 316-331. doi:10.1111/lcrp.12003

Hope, L., Memon, A., \& McGeorge, P. (2004). Understanding pretrial publicity: Predecisional distortion of evidence by mock jurors. Journal of Experimental Psychology: Applied, 10, 111-119. doi:10.1037/1076-898X.10.2.111

Johnson, M. K., Hashtroudi, S., \& Lindsay, D. S. (1993). Source monitoring. Psychological Bulletin, 114, 3-28. doi:10.1037/0033-2909.114.1.3

Kay M., \& Wobbrock. J. (2019). ARTool: Aligned Rank Transform for Nonparametric Factorial ANOVAs. doi:10.5281/zenodo.594511, R package version 0.10.6, https://github.com/mjskay/ARTool.

Lewandowsky, S., Ecker, U. K., Seifert, C. M., Schwarz, N., \& Cook, J. (2012). Misinformation and its correction: Continued influence and successful debiasing. Psychological Science in the Public Interest, 13(3), 106-131. doi: 


\section{$10.1177 / 1529100612451018$}

Lorek, J., Centifanti, L. C., Lyons, M., \& Thorley, C. (2019). The impact of individual differences on jurors' note taking during trials and recall of trial evidence, and the association between the type of evidence recalled and verdicts. PloS ONE, 14(2), e0212491. doi:10.1371/journal.pone.0212491

Mansouri, H., Paige, R. L., \& Surles, J. G. (2004). Aligned rank transform techniques for analysis of variance and multiple comparisons. Communications in Statistics-Theory and Methods, 33, 2217-2232. doi:10.1081/STA-200026599

Marquis, K. H., Marshall, J., \& Oskamp, S. (1972). Testimony validity as a function of question form, atmosphere, and item difficulty. Journal of Applied Social Psychology, 2, 167-186. doi:10.1111/j.1559-1816.1972.tb01270.x

Meade, M. L., McNabb, J. C., Lindeman, M. I., \& Smith, J. L. (2017). Discounting input from older adults: The role of age salience on partner age effects in the social contagion of memory. Memory, 25, 704-716. doi:10.1080/09658211.2016.1207783

Meade, M. L., \& Roediger, H. L., III. (2002). Explorations in the social contagion of memory. Memory \& Cognition, 30, 995-1009. doi:10.3758/BF03194318

Paterson, H. M., \& Kemp, R. I. (2006). Comparing methods of presenting post-event information: The power of co-witness suggestion. Applied Cognitive Psychology, 20, 1083-1099. doi:10.1002/acp.1261

Pritchard, M. E., \& Keenan, J. M. (1999). Memory monitoring in mock jurors. Journal of Experimental Psychology: Applied, 5, 152-168. doi:10.1037/1076-898X.5.2.152

Pritchard, M. E., \& Keenan, J. M. (2002). Does jury deliberation really improve jurors' memories?. Applied Cognitive Psychology, 16, 589-601. doi:10.1002/acp.816

Rich, P. R., \& Zaragoza, M. S. (2016). The continued influence of implied and explicitly stated misinformation in news reports. Journal of Experimental Psychology. 
Learning, Memory \& Cognition, 42, 62-74. doi:10.1037/xlm0000155

Roediger, H. L., \& McDermott, K. B. (1995). Creating false memories: Remembering words not presented in lists. Journal of Experimental Psychology: Learning, Memory, and Cognition, 21, 803-814. doi:10.1037/0278-7393.21.4.803

Roediger, H. L. III, Meade, M. L., \& Bergman, E. T. (2001). The social contagion of memory. Psychonomic Bulletin \& Review, 8, 365-371. doi:10.3758/BF03196174

Rosenhan, D. L., Eisner, S. L., \& Robinson, R. J. (1994). Notetaking can aid juror recall. Law and Human Behavior, 18, 53-61. doi:10.1007/BF01499143

Ruva, C. L. (2016). The impact of pretrial publicity and need for cognition on mock-jurors' decisions and deliberation behavior. International Journal of Psychology and Behavioral Sciences, 6, 20-31. doi:10.5923/j.ijpbs.20160601.0

Ruva, C. L. (2018). From the Headlines to the Jury Room: An Examination of the Impact of Pretrial Publicity on Jurors and Juries. In B.H. Bornstein and M.K. Miller (Eds.) Advances in Psychology and Law (Volume 3). Springer: Cham.

Ruva, C. L., \& Guenther, C. C. (2015). From the shadows into the light: How pretrial publicity and deliberation affect mock jurors' decisions, impressions, and memory. Law and Human Behavior, 39, 294-310. doi:10.1037/1hb0000117.

Ruva, C. L., \& Guenther, C. C. (2017). Keep your bias to yourself: How deliberating with differently biased others affects mock-jurors' guilt decisions, perceptions of the defendant, memories, and evidence interpretation. Law and Human Behavior, 41, 478-493. doi: 10.1037/lhb0000256

Ruva, C., \& LeVasseur, M. (2012). Behind closed doors: The effect of pretrial publicity on jury deliberations. Psychology, Crime and Law, 18, 1-22. doi: 10.1080/10683 16X.2010.502120

Ruva, C. L., \& McEvoy, C. (2008). Negative and positive pretrial publicity affect juror 
memory and decision making. Journal of Experimental Psychology: Applied, 14, 226235. doi:10.1037/1076-898X.14.3.226

Ruva, C., McEvoy, C., \& Bryant, J. B. (2007). Effects of pre-trial publicity and jury deliberation on juror bias and source memory errors. Applied Cognitive Psychology, 21, 45-67. doi:10.1002/acp.1254

Sharman, S. J., \& Powell, M. B. (2012). A comparison of adult witnesses' suggestibility across various types of leading questions. Applied Cognitive Psychology, 26(1), 4853. doi:10.1002/acp.1793

Thorley, C. (2016). Note taking and note reviewing enhance jurors' recall of trial information. Applied Cognitive Psychology, 30, 655-663. doi:10.1002/acp.3240

Thorley, C., \& Christiansen, P. (2018). The impact of own and others' alcohol consumption on social contagion following a collaborative memory task. Memory, 26, 727-740. doi:10.1080/09658211.2017.1404110

Thorley, C., Baxter, R. E., \& Lorek, J. (2016). The impact of note taking style and note availability at retrieval on mock jurors' recall and recognition of trial information. Memory, 24, 560-574. doi:10.1080/09658211.2015.1031250

van Koppen, P. J., \& Lochun, S. K. (1997). Portraying perpetrators: The validity of offender descriptions by witnesses. Law and Human Behavior, 21, 661-685. doi:10.1023/A:1024812831576

Wells, G. L. (1985). Verbal descriptions of faces from memory: Are they diagnostic of identification accuracy?. Journal of Applied Psychology, 70, 619-626. doi:10.1037/0021-9010.70.4.619

Wobbrock, J. O., Findlater, L., Gergle, D., \& Higgins, J. J. (2011, May). The aligned rank transform for nonparametric factorial analyses using only ANOVA procedures. In Proceedings of the SIGCHI conference on human factors in computing systems (pp. 
143-146). ACM.

Wright, D. B., Memon, A., Skagerberg, E. M., \& Gabbert, F. (2009). When eyewitnesses talk. Current Directions in Psychological Science, 18, 174-178. doi:10.1111/j.14678721.2009.01631.x

Wright, D. B., Self, G., \& Justice, C. (2000). Memory conformity: Exploring misinformation effects when presented by another person. British Journal of Psychology, 91, 189202. doi: $10.1348 / 000712600161781$ 